\title{
A New “Community” Organization Approach for Elderly Persons with Multiple Mental Disorders*
}

\author{
Yumi Oshita \\ Prefectural University of Hiroshima, Hiroshima, Japan
}

\begin{abstract}
This article presents a case study for the "community" approach to social work. It is the case of an elderly client whose social adaptation level had multiple problems associated with weakened networks at a higher rate area of seniors in Japan. Specifically, the "community” approach adopted here was the Refined Short-term Reconstructing Meaningful Life-worlds (RSRM), which defines "community” as a circular system of speech acts and meaning construction. This social constructionist approach is shown to improve the client's adaptation level in the "community" where a differentiation force is activated using circular questions. This force allows the client to make beneficial life-worlds. The RSRM also has a concrete intervention procedure. First, the client, who was in her eighties with depression, delusional disorder, slight dementia, and urination neurosis, was encouraged to tell her problematic story. To differentiate speech acts in her "community”, circular questions, positive reframing and solution-focused skills were used. Then she was encouraged to practice her newly acquired speech acts in her "community". She regained the ability to communicate with other persons with confidence, and she could extend the "community" networks to practice her newly acquired communication skills. Through her practices in her extended "community”, her multivariate problems were resolved.
\end{abstract}

Keywords: “Community”, Refined Short-term Reconstructing Meaningful Life-worlds (RSRM), circular questions, positive reframing, solution-focused skills

\section{Introduction}

Community ties and networks in Japan have grown weaker and interpersonal connections have generally become more and more attenuated. Therefore, the construction of the new community social work model which has a force to transform the dynamics as well as the structure of a community system will be required.

The "community" can be defined as the system of feedback loop of the information of the difference (Bateson, 1972). The definition of the "community" is changed from the area or residence to the composition which generated in the transaction with people. Bateson distinguished a map as a constructed reality from a metaphysical concept of an existing area. Then he explained the dynamics of a constructed reality using a concept of difference. The concept of "community" is a social system generated by a continuous exchange of information of a difference transmitted by speech acts between members. When a circular exchange movement of difference stagnates, problems to be solved will occur. The transactional exchange movement of difference

\footnotetext{
*Acknowledgements: This work was supported by JSPS KAKENHI Grant Number 16K04165. The author would like to thank the publication permission from the client and the staff in M-CGSC.

Yumi Oshita, Associate Professor, Faculty of Health and Welfare, Prefectural University of Hiroshima.
} 
consists of meaning constructions and speech acts. The problem in the "community" is generated by the inactivation of difference.

The staff in the Community General Support Center (CGSC) in Japan takes on the role of resolving the problem which occurred in the "community". M-CGSC is the CGSC in the area where there is a high rate of seniors (over 44 percent in 2015), solitude, welfare recipients, the survivors of bombing, and multiple-nationalities. It is difficult to generate resources to help all residents, especially elderly people, living alone in this social system. The practice of an effective "community" organization is required to solve these multiple problems which the elderly persons have.

The Refined Short-term Reconstructing Meaningful life worlds (RSRM) is a new narrative social work practice model which is composed of a unique fundamental theory as well as a unique approach to clinical practice. The basic theory proposed is a version of systems theory which has been influenced by social constructionism. The clinical application of this theory is composed of what can be called a "changing skills", as well as "changing procedure" and a measurement method (Oshita \& Kamo, 2011, 2014). It aims to provide a theoretical framework to explain the generative process of structuring and dynamics of "community" in terms of transactions. Moreover, it has the ability to clarify the direction of "community" organization approach. This "community" organization approach is presented in this article. The "community" is composed of interconnected rules of social behavior which are constructed by an exchange of information between members. This theorization of a dynamics and a structure of "community" from a social constructionism point of view clarifies the minimum elements that compose "community" system. The minimum elements are speech acts that send information of difference and the activities of meaning construction of speech acts. Therefore, these minimum elements are visualized as target points of transformation for the social worker. Moreover the clarification of these minimum elements can be utilized as a method to analyze and change a reciprocal mechanism between members where information is exchanged by their rule governed behaviors.

This newly generative "community" social work theory based on social constructionism is different from White's narrative approach and others who follow the typical narrative approach. Typical narrative approaches tend to focus on the problematic story constructed by uni-directional force generated by the discourse. Therefore, the typical narrative approaches do not explain the co-generative mechanism of a story. The RSRM approach, however, explains the co-generation process of problematic story by focusing on the multi-directional force of difference in transactions between persons. The dynamics and structure of the co-generation of "community” network are explained utilizing the person's narrative in a social transaction. In other words, this newer "community" social work theory understands better the power of the person as generator of his/her world construction.

\section{Methods}

\section{A Theoretical Basis of "Community” Organization}

A generative "community" in the RSRM model is defined as a structure of interpersonal transactions in which a vertical and a horizontal feedback loop operates. These feedback loops operate by the rules of speech acts and rules of meaning construction of them. CMM (Coordinated Management of Meaning) theory, which is a social theory, can explain the rules as consisting of constitutive rules and regulative rules (Cronen, Pearce, \& Tomm, 1985). Constitutive rules are the rules used to construct the meaningful life world and regulative rules are the rules used to choose the speech acts in the transaction. These rules are generated in two feedback loops 
as shown in Figure 1.

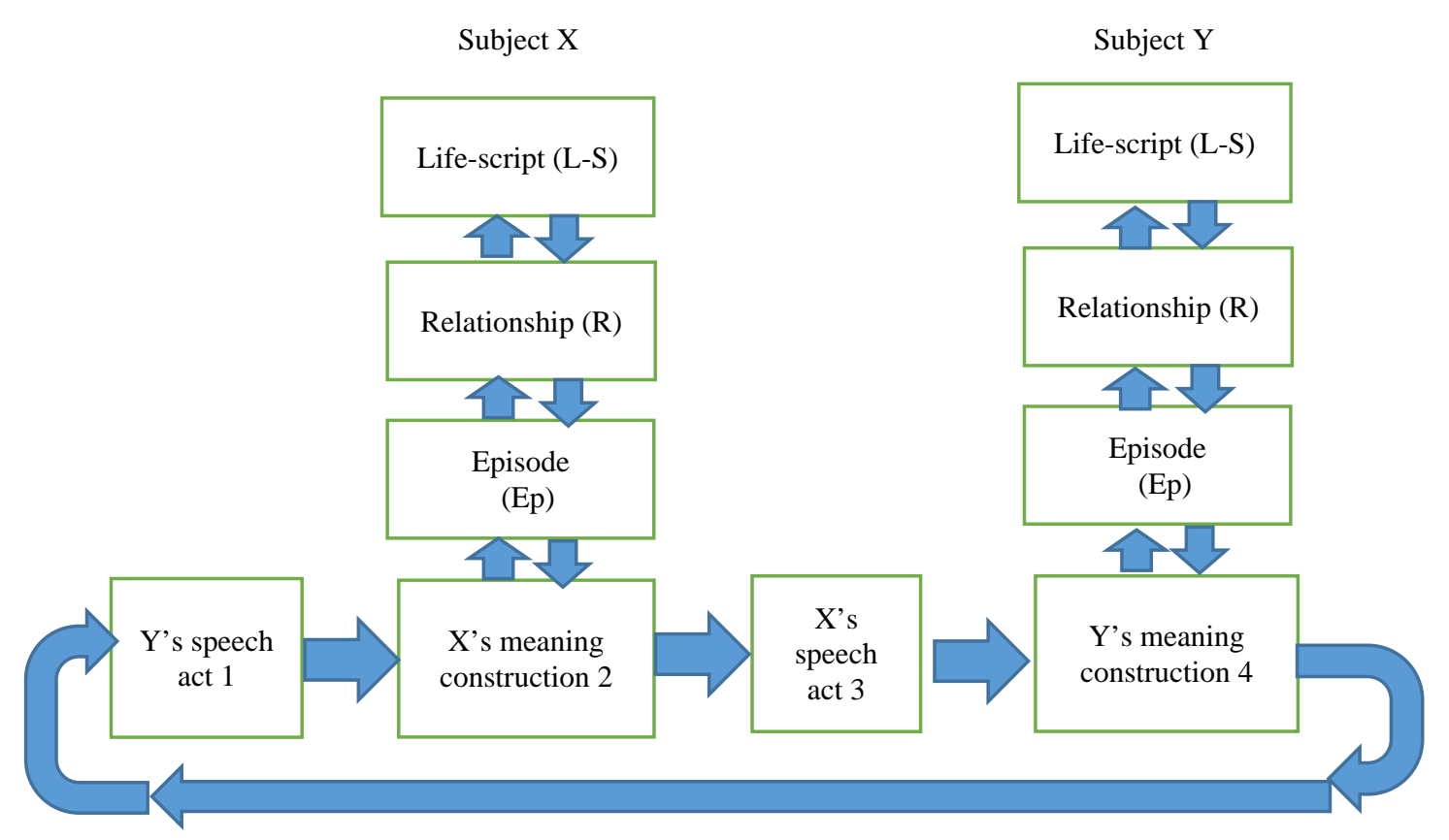

Figure 1. Two types of feedback loops and the structuring of the "community".

Figure 1 is diagram which illustrates a mechanism of two types of feedback loops based on CMM. A minimum dyadic subsystem in a "community" is generated by these feedback loops. The horizontal feedback loop is composed of the activities of speech acts and meaning construction in the transaction between X and Y. The up and down arrows indicate the vertical feedback loop that generates a meaning structure. Each level in a meaning structure operates as a context that creates other levels of meanings. These levels are not fixed.

An occurrence of a small difference develops a force of differentiation in two feedback loops. A differentiation of rules within one level in the vertical feedback loop then operates as a force of differentiation in the horizontal feedback loop. For example, the differentiation of a meaning construction rule of an episode operates as a transformative force to differentiate the rules of other levels of meaning structure; relationships or life scripts. Then, a differentiation of a vertical structure triggers a differentiation of a rule in the selection of a speech act in the horizontal feedback loop. On the contrary, the differentiated speech act becomes a trigger to transform a structure of meanings. Moreover the horizontal and vertical transformation force in this dyadic system extends to a transformation of a dynamics in other systems, if a skillful intervention is performed. As a result, the transformation of a whole "community” system begins. In other words, the generation of a small change in a mechanism of vertical feedback loops and horizontal feedback loops triggers a transformation of a whole "community" structure.

\section{The Features of Intervention Skills in RSRM}

The RSRM has a new set of skills composed of circular questions (Tomm, 1985, 1987a, 1987b, 1988) as the main skills. Also, as to the subsequent skills, solution focused questions (De John \& Berg, 2002) and paradoxical prescription (Weeks \& L’Abate, 1982) are connected (Oshita \& Kamo, 2011; Oshita, 2016). This utility of the intervention skills stand in contrast different to White's narrative approach (White, 1990). For 
White's narrative approach, externalization is the main skill that provides helping activities to set a client free from a suppressive dominant story, and to actualize a new story that presents him/her a new method of a world construction.

In the RSRM approach, circular questions are used to differentiate a speech act or a meaning construction of a speech act in a transaction. Then the social worker chooses an intervention to extend a minimum change to a whole system using the skills set of circular questions, solution focused approach's questions and paradoxical intervention skills. Original circular questions have sub-categories of difference questions and contextual questions (Tomm, 1985). Difference questions are the questions to ask the client about the difference between things, believes, and action etc. Contextual questions are the questions for the client about the contextual difference between life-script, relationship, episode and speech act. Moreover, original circular questions are divided into two types of questions depending on the aim of differentiation (Tomm, 1985). The one is Descriptive circular questions (DCQ). The other is reflexive circular questions (RCQ). DCQ aims to describe the sequence of the elements of one problematic episode which composed of the client's complaint. RCQ aims to reflect on the elements of a sequence and thus it activates a force of differentiation in a transaction, and transforms the sequential problematic story client described.

Additionally, in the RSRM approach, compliments, exceptional questions, and miracle questions which were invented in the solution focused brief therapy are adopted as the subsequent changing skills. Also, paradoxical prescription and positive reframing are used as combination skills in RSRM. In the following case study, circular questions are used as the main skills and compliment, positive reframing as secondary skills to generate and activate a difference. Compliment is categorized when the episode is evaluated positively, and positive reframing is categorized when the meaning of the episode changes from negative to positive.

\section{Case Study}

This case is of an elderly person in her 80's whose problematic adaptation improved by a newly systematized "community" organization method based on the RSRM model. The mechanism of the transformation process of her adaptation is analyzed intensively through the intervention process using specific skills set. The effectiveness of a new "community" organization is illustrated.

\section{Case Background}

A client was a female in her eighty who lives alone. She was hospitalized for treatment of a leg bone fracture. Her social relationships had rapidly deteriorated after some of her close friends' deaths while she was hospitalized for treatment of a bone fracture. After leaving hospital, though she started to use day care services, she gradually did not use day care services and also had withdrawn from other social relationships. At the same time, she had expressed her depressive complaint, slight dementia (she bought the same food items several times a day), delusional distortion, an urination neurosis. At last, her "community" as a structure of human transactions was only M-Community General Support Center (M-CGSC) where she could sometimes visit.

\section{Intensive Assessment and Intervention Plan}

The social worker assessed the client's typical problematic withdrawal pattern in her "community", focused on her speech act and meaning construction. While the client spent the day-time in M-CGSC, she was usually crying with her face lying on the desk throughout the day. When the social worker asked her about her condition, she responded as follows: (1) I am afraid to be alone, (2) I do not see any meaning to life, (3) It is 
better for me to die than to live long, and (4) I do not have motivation to go to the day care center. The social worker tentatively assessed that these complaints were strengthened by transactions in M-CGSC.

Figure 2 shows the mechanism for the generation of the client's complaint in her "community" (M-CGSC). The generative mechanism of the client's complaint can be explained as follows. The client complained "I am afraid to be alone”. Then, the staff encouraged the client by saying, "You shouldn’t worry”. This message activated her negative meaning construction in her vertical feedback loop. The negative meaning construction of the staff's message became a force to construct other levels of meaning structure among Ep, R, and L-S negatively. The client responded to the same message with tears. This speech act operated as a contextual force to choose the staff's continually encouraging message. At this stage, her adaptation level had deteriorated in a way represented by a horizontal feedback loop. The mechanism of the increase in her maladaptation is assessed as follows. The staff in M-CGSC which was the client's only "community” sent an encouraging message to her. This operated as a pre-figurative force to actually aggravate her interpersonal relationships. Her negative meaning construction to staff's messages functioned as a vertical contextual force to strengthen her negative meaning structure. It defined her interpersonal relationship and her whole life world in negative terms. This strengthened negative meaning structure triggered the operation of her horizontal feedback loop. Thus her complaints increased the staff's encouraging messages. Conversely the staff's responses strengthened the client's complaints in the horizontal feedback loop.

These co-generative feedback loops between the vertical and horizontal feedback loop produced the pseudo solution activities between staff and the client.

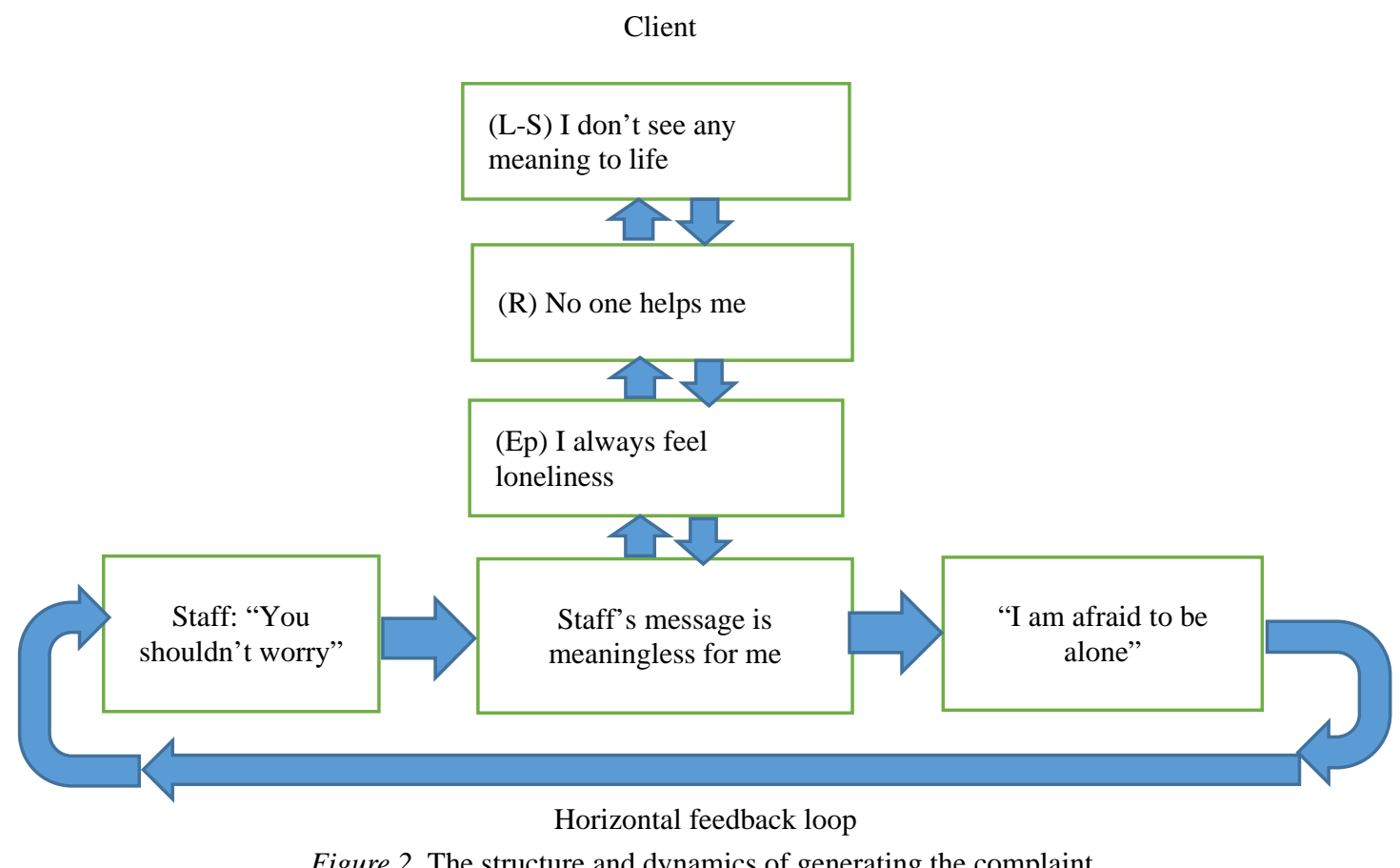

The intervention plan for this client was planned based on these assessments. The framework which was utilized was designed to help her acquire problem solving activities through activating a differentiation force both feedback loops in her "community". Then, the plan aimed at the expansion of new networks of her 
“community”.

\section{Intervention Strategy for Generating the Client's New “Community”}

To transform the client's "community", the team approach which was composed of individual sessions and group activities was adopted. The social worker in the M-CGSC planned the specific intervention strategy to generate a new "community" for the client. First, the client was helped to find new solution activities through one intensive individual interview by the social worker. Secondarily, in group activities, the staff helped the client to practice her newly acquired solution activities in order to actualize and stabilize them. Thirdly, in an individual session, her new solution activities in M-CGSC are evaluated. Then, the client's resolution activities were strengthened through discovering her solution skills, implementing them, and reflecting on the effectiveness of her resolution activities.

\section{Intervention Process}

The following data illustrates the concrete intervention process to generate the solution skills in M-CGSC.

1CL: I feel loneliness (with tears). Would you permit me to stay here (M-CGSC)? I feel alone in my home because all the rooms around my house are vacant. (Complaint)

2SW: You feel alone in your home....and so you come here...I exactly understand the meaning for your coming here. You are trying to reduce your loneliness by coming here (Positive reframing: PR). Could you tell me about your loneliness? (DCQ; descriptive circular questions)

The client complained about her troubles to the social worker as in 1CL. The social worker positively reframed her complaint (2SW). Furthermore, the social worker encouraged the client to describe her solution activities. Then, the message, 2SW, was sent to the client to create a small positive difference of her meaning construction of other's speech acts in M-CGSC.

3CL: I know I should not come here often, but this is the only place where I can feel less lonely even though I am usually crying here.

4SW: You can reduce your loneliness not only by coming here but also staying here (compliment). Could you tell me in more detail about how you are dealing with your loneliness here? (DCQ)

In 3CL, the client described the resolution of the meaning of her staying at M-CGSC as well as her coming there. Then, the social worker responded 3CL positively using compliment in 4SW. In addition, DCQ was used to help her describe the specific resolved transaction of her loneliness in her "community" in the M-CGSC.

5CL: I always sit beside the entrance door.

6SW: I see, you always sit beside the entrance door... and then what do you do there...(DCQ)

Triggered by the social worker's DCQ in 4SW, the client positively changed the meaning of her activities in M-CGSC. She described the episode in which she performed resolution activities to cope with her anxiety such as 5CL. Here, the social worker, using DCQ (6SW), encouraged the client to describe the elements in this positively reconstructed sequence. 
7CL: I look outside and can easily see the people going back and forth ... and I can respond to the guests who visit the M-CGSC right away.

8SW: Oh, really? The reason you always sit beside the entrance door is to help us by greeting our guests in order to help the guests not feel anxious! (PR) When you are greeting our guests, were you able to stop crying? How were you able to choose these activities? (DCQ)

Then the client was thus able to sequentially explain the elements of her episode which enabled her to reduce her anxieties sitting beside the entrance door (7CL). The social worker had activated the positive meaning of these activities for the client, as greeting activities, in order to reduce the guest's anxieties rather than the staff in M-CGSC (8SW). This social worker's skill consisted of positive reframing of her behaviors of crying and sitting beside the entrance door as greeting activities. Moreover, the social worker encouraged her to specifically describe elements of her episode of the greeting using DCQ (8SW).

9CL: Well, I'm always aware of how busy you and your staff are..., therefore I decided to interact with the guests when the staff could not greet the guest right away.

10SW: I think that we had better say thank you to you for helping our guests feel more at ease (compliment).

The client could describe her ability to observe the staff's activities and to decide to choose greeting activities in 9CL. Also, the client's activities were evaluated as solution activities to reduce the other guests' anxiety. The social worker complimented the client's skills of observation and her helping activities for the guests (10SW).

Through this individual session, the client evaluated her ability to invent her resolution activities in order to reduce her anxiety. Moreover, she visualized her ability to help the guests and the staff in M-CGSC.

The transformation of her meaning construction to her behavior and the actualization of new solution behaviors was a trigger to differentiate the horizontal feedback loop that had generated her interpersonal world. At the same time, the generation of these activities operated as a contextual force to differentiate the vertical feedback loop of her reality construction. In this differentiation process, her definition of an episode and interpersonal relationships were perturbed by a generation of these activities. That is, her resolution activities in the "community" in M-CGSC were elicited through this individual session.

The utility of intervention skills in the individual session was summarized as follows. The combination utility between circular questions (DCQ) and compliment or PR technique was continuously used in 2SW, 4SW, and 8SW. This utility elicited the client's description of 9CL.

\section{Transformation of Horizontal Feedback Loop}

The next step in the intervention process was to have client engaged in group activities, which were done to intensively activate the difference in her transaction in the "community". Before implementation of group activities, the social worker attempted to positively evaluate the client's activities in M-CGSC with her staff. Especially, the staff in M-CGSC was encouraged to discover the client's specific activities related to the greeter activities, instead of her crying and other depressive state activities. The team member was able to additionally identify and clarify her specific greeting activities which the client had not explained. Then, the staff decided to respond with compliment messages. For example, when the client often offered her chair and served a cup of tea to the guests in M-CGSC, the staff actively praised each activity with words of appreciation. The client's 
crying and depressive complaints became less and less.

The social worker and staff in M-CGSC intensively and repeatedly responded positively to the client's greeter activities. This was constituted new helping activities which the staff chose to deal with the client. Previously, staff would regard such a person as a "mental patient" suffering from her emotional problems. However, in RSRM under the guidance of the social worker based on the RSRM model, they could adopt a new approach. In other words, the staff abandoned their old role behavior in which they obeyed the rules about dealing with "mental patients". As a result, the client began to choose a role of organizing these new role behaviors. These transformations of two role behaviors were co-generated. Then, the rule of the horizontal feedback loop in transactions in M-CGSC as her "community" began to transform. This is the horizontally transformed mechanism in which her complaints about her anxieties began to be reduced.

\section{The Transformation of Vertical Feedback Loops}

At this point, in order to enforce the client's abilities to implement her new resolution activities, the staff assigned her a formal role as greeter in M-CGSC. They give her a name tag that symbolized and concretized her formal role of greeter. It triggered the change of the dynamics of the client's vertical feedback loop. She produced episodes that make her believe her abilities to choose appropriate role in her M-CGSC. The transformed meaning of the episode operated as a contextual force to change the definition of her interpersonal relationship. Inversely, this transformation of a meaning structure influenced her selection of new speech acts.

\section{The Stabilizing Co-generative Mechanisms Between the Horizontal and Vertical Feedback Loops}

Next, in the individual session, the social worker helped the client intensively reflect on the results of her performance of greeter role using circular questions (RCQ). The RCQ is a skill which encourages a client to clarify a structure and a new dynamic for implementing new life worlds. The social worker complimented her story about the implementation of the greeter role produced by her reflection.

1SW: Thank you for your great help with greeting the guests at our center today. I think you handled more work than usual (compliment). How do you feel now? (RCQ; reflexive circular questions)

2CL: I did not think I did more work than you or your staff today.

The social worker tried to evaluate her activities positively and encouraged her to reflect on her greeter's activities all day long (1SW). Then the client expressed appreciation for the staff's work (2CL).

3SW: Well, we found you worked harder than us today, I imagined you are very tired. We are very surprised because you could keep performing your greeter role very carefully...you tried to help us and cheer us up all day long, right? ... (Compliment)

4CL: Of course. I want to do for you whatever I can.

Then, the social worker chose compliment messages to help her feel reassured about her communication abilities (3SW). The client then expressed herself as a helper for the staff in M-CGSC (4CL). The client's explanation of 4CL illustrated the differentiated definition of herself in her life world (L-S). The client redefined herself as a person who can help others, not as a person who always needed others' help. 
6CL: I am good at calculation work.

Then, the social worker encouraged the client to clarify her new resolution activities of helping the staff in addition to greeter role for the guests in 5SW. She could assume the role of accounting assist (6CL). It meant that she could find the activities to enforce her transformed interpersonal relationship (R). Moreover, the definition of her whole life worlds (L-S) began to change directed by this contextual force of the changed R. This is the vertical transformation of her life worlds.

7SW: So, shall we ask you to help with calculation work in addition to being a greeter the next time? (RCQ)

8L: Sure.

Then, the social worker asked her to reflect on the possibility of accounting assist, adding to the greeter role by RCQ (7SW). She agreed to add the new role activities (8CL).

9SW: I feel your performance these days has totally changed from the activities of complaining about your loneliness the other day (compliment)... Could you explain to me how you were able to change your behavior like this? (RCQ)

10CL: I have not changed anything at all. I am just very glad that you and your staff have given me a chance to perform some useful activities such as a greeter, as well as accepting me to come and spend time here as a guest. Well, in this case, I would like to do everything that I can do for you. Please feel free to let me know anything you need help with.

11SW: You are an excellent support for us as well as a good greeter for our guests.

The social worker encouraged her to self-reflect by comparing her new life situation with her past which was dominated by anxiety; the present in which she performed as helper served as a differential force (9SW) (RCQ). Then, the client did not describe her change, but rather the positively transformed meanings of the staff's speech acts (verbal and nonverbal). The client acquired the ability to construct these speech acts as messages of acceptance by the staff in her "community". Thus we see a redefined of "community" by the client. Also, the client could construct her activities as helping activities for the staff in M-CGSC.

This differentiated horizontal interpersonal transaction operated as a context to reorganize her vertical meaning structure. The client expressed a transformation in the definition of her relationship between her and the staff in M-CGSC (10CL). The social worker responded with the positive evaluation of the client's activities which were chosen on the context of her description (10CL) as supporter for all staff (11SW).

Conversely, her differentiated vertical feedback loop gave her a context with which to sustain two newly acquired formal role behaviors. This co-differentiation of horizontal and vertical feedback loops is the mechanism that reorganized her "community" as a structure of the intensive interpersonal relationship. At the same time, her complaints decreased.

To activate the co-differentiation mechanism, circular questions were mainly used. A compliment and positive reframing were utilized as combination skills with circular questions to enforce and actualize the differences which were generated by circular questions.

\section{Expanding Her “Community” Outside M-CGSC}

After individual intervening to reflect on her problem resolution abilities, the social worker planned to expand the client's new transactions outside M-CGSC. The social worker kept encouraging the client to 
perform her roles as helper for the staff by taking a role of greeter in various other social events which the M-CGSC sponsored as well as in the M-CGSC. The client participated in many social events in her local areas and attempted to perform some other social roles. A few months later, the client voluntary invented a new social relationship with another elderly person G, who sometimes visited M-CGSC. The elderly person G was in her nineties and had a slight physical disability. The client sometimes helped the elderly person $G$ when $G$ stood up from the chair and sat down in the chair. Then, the client voluntary started to go to the day care center where she had previously refused to go in order to help the elderly person $\mathrm{G}$ as a friend and helper. This helping activity for the elderly person $G$ operated to reduce her anxiety about being alone. Her "communities" were expanded and her psycho-social situation was totally changed.

\section{Results}

Through intensive assessment and intervention, the structure and dynamics of her "community" was changed totally and expanded. Figure 3 demonstrates the transformation of the client's "community" through the intervention.

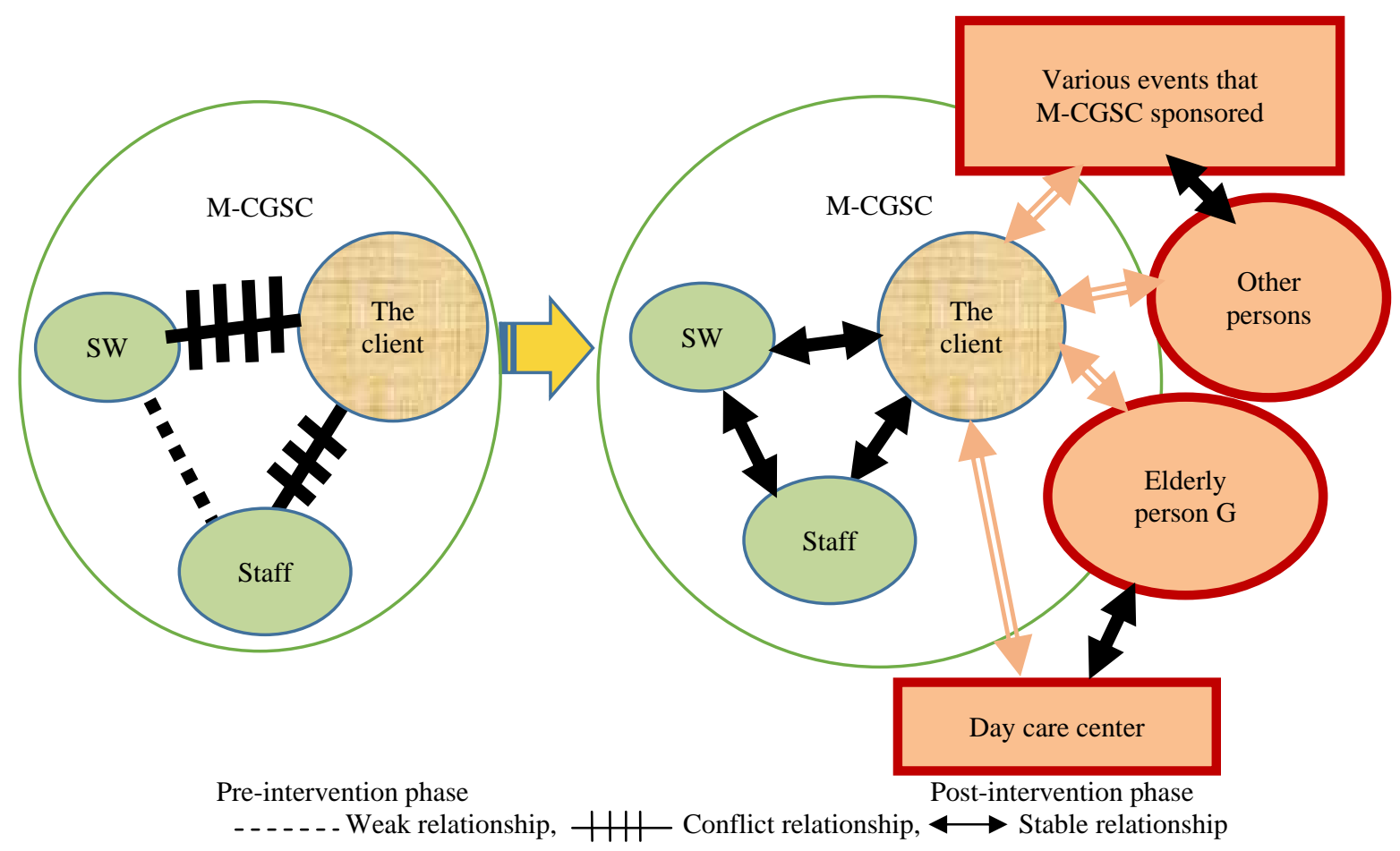

Figure 3. Transformation of the client's “community” between pre-intervention and post-intervention.

The large circle on the left was M-CGSC which was her "community" in the pre-intervention phase. Her transactions with the staff and social worker in her "community" were antagonistic at that time. Moreover, the transaction with the staff and a social worker was weak. Then, the social worker intervened in this system to reorganize them in her "community". As a result, her "community" totally changed on the right circle and re-organized as her new "community" networking with four subsystems outside M-CGSC in Figure 3. Two squares and two circles outside M-CGSC were added to her "community" through these intervention activities.

Through the generation process of her new "community" illustrated in the right in Figure 3, the client's delusional distortion, depression symptoms, and urination neurosis disappeared. Also, there was an 
improvement in her cognitive functioning.

\section{Discussion}

There are four points to be discussed. First, this RSRM practice model represents the ability to provide the theoretical framework to explain the generative mechanism of "community" networks. The definition of the generative "community" as a transaction network was a useful theoretical tool that provides a basis for a new "community" social work practice. The theory of the generative "community" explains the mechanism of therapeutic "community" formation as follows. It defines community dynamically as a structure of interconnected rules followed in the transactions among members. If a rule obeyed problem amplifying behavior is changed, this perturbation will extend throughout the whole "community" system, the structure and dynamics of a whole system will be perturbed. Then a structure of interconnected rules of transactions having an ability of problem resolution generates throughout a whole "community" system which directs then the system members to choose new resolution activities.

Secondly, this theoretical basis provided social workers a new framework for helping activities in the "community". It presented social workers with a minimalist resolution method. The problem resolution mechanism of new "community" organization approach based on the RSRM can be summarized by following three stages. The first stage is meant to encourage the client to describe intensively her activities in the "community" and differentiate them using DCQ. She differentiated her adaptive activities and invented a new effective method of adaptation. The second stage was aimed at actualizing and practicing her activities using compliment, RCQ, and PR skills. Her activities to reduce her anxiety were called as a greeter provided a meaning for her solution activities. She confirmed her abilities to communicate effectively by practicing her newly acquired communication skills. The third stage aimed at re-describing the situation in which her anxiety arose, reflecting on it and differentiating her activities and practicing them in order to generalize her new problem resolution method. This method was applied when the client generated new interpersonal relationships in a new "community". In other words, the transformation of the generative "community" was accomplished through generating a minimum differentiation in the sequence of meaning construction and speech acts. The force of generating a difference could expand to a whole "community" system. Moreover, this case study presented a method in which the client could extend a minor change to a whole "community" system and constructed new "community".

Thirdly, a new "community" approach based on the RSRM model can be utilized by combining both two types of forms which are individual sessions and group activities. The intensive individual counselling was utilized to intervene in the generative process of the individual problems and the group activities were utilized to transform and stabilize a problematic horizontal feedback loop. The staff in M-CGSC was composed of multiple professionals, such as social workers, nurses, care givers, care managers, physical therapist and occupational therapist, in the group activities. All professionals transcended their previously held limited role definitions. Then, a new helping network system having problem solving force was structured in M-CGSC.

Fourthly, the usefulness of these skills sets for generating "community" networks was demonstrated. In individual sessions, the utility of using DCQ, RCQ, and PR has been illustrated to generate a small difference in a "community", and extend its change to a whole community system. In group activities, the PR provides useful skills to activate and stabilize the client's resolution activities. The combination of circular questions (DCQ), PR and compliment was contributed to identify the client's resolution activities and discover the 
resolution of meaning of client's activities in the horizontal feedback loop. Also, the combination of circular questions (RCQ), PR and compliments was effective to differentiate the meaning of levels in the vertical feedback loop and stabilize the rules of client's resolution activities in the transactions in her "community". These skills are used to differentiate minimum elements composing a transaction in a "community". It has the force to perturb the dynamic of "community" by activating a differentiation force and to stabilize a newly generated "community" in which the rules of resolution activities operated.

\section{Conclusion}

A usefulness of this new "community" organization approach based on the RSRM model based on a particular theoretical model and set of skills, was presented through the successful case study for an elderly person with multiple mental disorders.

This case analysis clarified her problem resolution mechanism as the "community” re-organization process where the mutual-transformation mechanism between the horizontal and the vertical feedback loops operated. The re-organization process which generated adaptive speech acts as well as meaning constructions of other peoples' messages, using social worker's and the staff's specific transformation skills, contributed to the reconstruction of her meaningful life-worlds.

Also, the staff in M-CGSC which was composed of multiple professionals, such as social workers, nurses, care givers, care managers, physical therapist and occupational therapist, in the group activities had acquired the skills to transcend their previously held limited role definitions utilizing the RSRM model.

In conclusion, a new "community" organization approach based on the RSRM model can provide an effective transformation using the combination of group activities and individual sessions for the professionals as well as the client.

\section{References}

Bateson, G. (1972). Steps to an ecology of mind. Chicago: The University of Chicago Press.

Cronen, V. E., Pearce, W. B., \& Tomm, K. (1985). A dialectical view of personal change. In J. Gergen, \& K. E. Davis (Eds.), The social construction of the person (pp. 203-224). New York: Springer-Verlag.

De John, P., \& Berg, I. K. (2002). Interviewing for solutions (2nd ed.). Belmont, CA: Brooks/Cole.

Oshita, Y. (2016). Narrative social work practice for HIV/AIDS clients. Universal Journal of Public Health, 4(2), 108-119.

Oshita, Y., \& Kamo, K. (2014). A new intervention skills and measurement method for clinical social work practice. Japanese Journal of Social Welfare, 54(5), 11-22.

Oshita, Y., \& Kamo, K. (Eds.) (2011). Reconstructing meaningful life worlds: A new approach to social work practice. Bloomington, IL: iUniverse.

Tomm, K. (1985). Circular interviewing: A multifaceted clinical tool. In D. Campbell, \& R. Draper (Eds.), Applications of systemic family therapy: The Milan approach (pp. 33-45). New York: Grune and Stratton.

Tomm, K. (1987a). Interventive interviewing: Part 1. Strategizing as a fourth guidelines for the therapist. Family Process, 26, 3-13.

Tomm, K. (1987b). Interventive interviewing: Part 2. Reflexive questioning as a means to enable self-healing. Family Process, 26, 167-183.

Tomm, K. (1988). Interventive interviewing: Part 3. Intending to ask lineal, circular, strategic or reflexive questions? Family Process, 27, 1-15.

Weeks, G. R., \& L’Abate, L. (1982). Paradoxical psychotherapy: Theory and practice with individuals, couples, and families. New York: Brunner/Mazel.

White, M., \& Epston, D. (1990). Narrative means to therapeutic ends. New York: Norton. 